\title{
STAT3 $\beta$ is a tumor suppressor in acute myeloid leukemia
}

Petra Aigner, ${ }^{1}$ Tatsuaki Mizutani, ${ }^{1,2}$ Jaqueline Horvath, ${ }^{1,2}$ Thomas Eder, ${ }^{1,3}$ Stefan Heber, ${ }^{4}$ Karin Lind, ${ }^{5}$ Valentin Just, ${ }^{1}$ Herwig P. Moll, ${ }^{4,6}$ Assa Yeroslaviz, ${ }^{7}$ Michael J. M. Fischer, ${ }^{4}$ Lukas Kenner, ${ }^{1,8,9}$ Balázs Györffy, ${ }^{10,11}$ Heinz Sill, ${ }^{5}$ Florian Grebien, ${ }^{1,3}$ Richard Moriggl, ${ }^{1,12}$ Emilio Casanova, ${ }^{1,4,6}$ and Dagmar Stoiber ${ }^{1,2,13}$

${ }^{1}$ Ludwig Boltzmann Institute for Cancer Research, Vienna, Austria; ${ }^{2}$ Institute of Pharmacology, Center for Physiology and Pharmacology, Medical University of Vienna, Vienna, Austria; ${ }^{3}$ Institute of Medical Biochemistry, University of Veterinary Medicine Vienna, Vienna, Austria; ${ }^{4}$ Institute of Physiology, Center for Physiology and Pharmacology, Medical University of Vienna, Vienna, Austria; ${ }^{5}$ Division of Hematology, Medical University of Graz, Graz, Austria; ${ }^{6}$ Comprehensive Cancer Center, Medical University of Vienna, Vienna, Austria; ${ }^{7}$ Computational Systems Biochemistry Group, Max Planck Institute for Biochemistry, Martinsried, Germany; ${ }^{8}$ Clinical Institute of Pathology, Medical University of Vienna, Vienna, Austria; ${ }^{9}$ Unit of Pathology of Laboratory Animals, University of Veterinary Medicine Vienna, Vienna, Austria; ${ }^{10}$ MTA TTK Lendület Cancer Biomarker Research Group, Institute of Enzymology, Hungarian Academy of Sciences, Budapest, Hungary; ${ }^{11}$ 2nd Department of Pediatrics, Semmelweis University, Budapest, Hungary; ${ }^{12}$ Institute of Animal Breeding and Genetics, University of Veterinary Medicine Vienna, Vienna, Austria; and ${ }^{13}$ Division of Pharmacology, Department Pharmacology, Physiology and Microbiology, Karl Landsteiner University of Health Sciences, Krems, Austria

\section{Key Points}

- The STAT3 $\beta / \alpha$ mRNA expression ratio in AML patients is a favorable prognostic marker and positively correlates with overall survival.

- Transgenic Stat3 $\beta$ expression delays disease progression and prolongs overall survival in AML mouse models.
Signal transducer and activator of transcription 3 (STAT3) exists in 2 alternatively spliced isoforms, STAT3 $\alpha$ and STAT3 $\beta$. Although truncated STAT3 $\beta$ was originally postulated to act as a dominant-negative form of STAT3 $\alpha$, it has been shown to have various STAT3 $\alpha$ independent regulatory functions. Recently, STAT3 $\beta$ gained attention as a powerful antitumorigenic molecule in cancer. Deregulated STAT3 signaling is often found in acute myeloid leukemia (AML); however, the role of STAT3 $\beta$ in AML remains elusive. Therefore, we analyzed the STAT3ß/ $\alpha$ messenger RNA (mRNA) expression ratio in AML patients, where we observed that a higher STAT3 $\beta / \alpha$ mRNA ratio correlated with a favorable prognosis and increased overall survival. To gain better understanding of the function of STAT3 $\beta$ in AML, we engineered a transgenic mouse allowing for balanced Stat $3 \beta$ expression. Transgenic Stat $3 \beta$ expression resulted in decelerated disease progression and extended survival in PTEN- and MLL-AF9-dependent AML mouse models. Our findings further suggest that the antitumorigenic function of STAT3 $\beta$ depends on the tumor-intrinsic regulation of a small set of significantly up- and downregulated genes, identified via RNA sequencing. In conclusion, we demonstrate that STAT3 $\beta$ plays an essential tumor-suppressive role in AML.

\section{Introduction}

Signal transducer and activator of transcription 3 (STAT3) is a key transcription factor in cell proliferation, maturation, and survival and hence involved in several oncogenic pathways. Although STAT3 is most commonly described as an oncogene in cancer, evidence also shows its role as a tumor suppressor. ${ }^{1-8}$ This opposing role of STAT3 in cancer depends considerably on its expression as different isoforms. ${ }^{1,9}$ Alternative splicing gives rise to full-length STAT3 $\alpha$ and truncated STAT3 $\beta$. STAT3 $\beta$ variants lack the canonical STAT3 $\mathrm{C}$-terminus and instead contain 7 unique amino acids, resulting in enhanced DNA binding affinity. ${ }^{10}$ Both isoforms are ubiquitously expressed; however, although the loss of STAT3 $\alpha$ leads to embryonic lethality in mice, STAT3 $\beta$ is not required for viability. ${ }^{11}$ Accordingly, STAT3 $\beta$ was originally described as a dominant-negative regulator of STAT3. ${ }^{10,12,13}$ Despite that, several studies have postulated an active regulatory role for STAT3 $\beta$ and identified a large number of STAT3 $\beta$-specific target genes. ${ }^{1,13-16}$ Recently, STAT3 $\beta$ has gained attention as a powerful antitumorigenic molecule, as shown for melanoma, esophageal squamous cell carcinoma, and breast, lung, and colon cancers. ${ }^{17-24}$ 
STAT3 has been shown to be constitutively active in AML cell lines and patients, causing a proliferative advantage and apoptosis protection. ${ }^{25-28}$ In addition, STAT3 activity has been associated with short disease-free survival in a subset of AML patients. ${ }^{29-32}$ As a consequence, STAT3 became an attractive therapeutic target in AML, but results from early clinical studies with STAT3 inhibitors have shown moderate effectiveness. ${ }^{28,33-35}$ In contrast to these studies, Redell et $\mathrm{al}^{36}$ described a protective role of increased STAT3 phosphorylation upon cytokine stimulation in AML patients, correlating with high disease-free survival. These conflicting results in AML might indicate that the impact of STAT3 inhibition in different patient subsets can vary as a result of its heterogeneous biological context. $^{37}$

An improved understanding of the biological functions of STAT3 isoforms in $A M L$ is therefore required. Here, we conducted an extensive study regarding the specific role of STAT3 $\beta$ in AML. We found that the balance of STAT3 isoform expression in AML patients can serve as a favorable prognostic tool. Furthermore, we demonstrate that the transgenic expression of STAT3 $\beta$ impairs leukemia progression. Taken together, our data identify STAT3 $\beta$ as a novel tumor suppressor in AML.

\section{Patients and methods}

\section{AML patients}

This study was approved by the ethics committees of the Medical Universities of Graz and Vienna (Austria) and conducted according to the Declaration of Helsinki. Written informed consent was obtained. Diagnostic peripheral blood (PB) and bone marrow (BM) samples from AML patients were enriched for mononuclear cells using Ficoll (GE Healthcare, Milan, Italy) density-gradient centrifugation before freezing in fetal bovine serum (Gibco; Thermo Fisher Scientific, Waltham, MA) with 10\% dimethyl sulfoxide (Sigma Aldrich, St. Louis, MO), as previously described. ${ }^{38}$ All samples contained $>80 \%$ blast cells after enrichment. Healthy $\mathrm{CD} 4^{+}$hematopoietic stem and progenitor cells (HSPCs) were collected from umbilical cord blood and enriched by magneticactivated cell sorting (Miltenyi Biotech, Gladbach, Germany).

Cytogenetic risk stratification of patients into favorable, intermediate, and adverse subgroups was applied according to the Medical Research Council classification scheme. ${ }^{39}$ In a proportion of patients, information on the mutational status of the FLT3, NPM1, and $C E B P A$ genes was available. Only patients receiving treatment with curative intention (chemotherapy with or without allogeneic hematopoietic stem cell transplantation) were included in the analysis of overall survival as defined by the European LeukemiaNet 2017 guidelines. $^{40}$ In accordance with literature describing an association of oncogenic FLT3 mutations with JAK/STAT activity, primarily STAT5 and STAT3, we furthermore excluded patients with a confirmed $F L T 3$ mutation in survival analysis. ${ }^{41-46}$

\section{Generation of Stat3 $\beta$ transgenic mice}

A Stat3 $\beta$ expression cassette containing the CAGGS promoter, a loxP-flanked (floxed) transcriptional/translational stop cassette, $\mathrm{N}$-terminus FLAG-tagged Stat $3 \beta$ mouse complementary DNA (cDNA), internal ribosomal entry site (IRES)/yellow fluorescent protein (YFP), and a bovine growth hormone-derived polyadenylation signal flanked by attB sites was assembled by conventional cloning. The Stat $3 \beta$ expression cassette was integrated into a bacterial artificial chromosome (BAC) containing the Rosa26 locus (RP24-85L15) by PhiC31 integrase-mediated cassette exchange. $^{47}$ Rosa26-modified BAC DNA was purified ${ }^{48}$ and microinjected into the pronucleus of $\mathrm{C} 57 \mathrm{BL} / 6$ oocytes.

\section{Animal studies}

Animal experiments were approved by the Animal Ethics Committee of the Medical University of Vienna and the Austrian Federal Ministry of Education, Science and Research. Mice were bred and kept under pathogen-free conditions at the Institute of Pharmacology, Medical University of Vienna (Vienna, Austria). Stat3 $\beta$ transgenic $\left(\right.$ Stat $\left.3 \beta^{\mathrm{TG}}\right)$ mice were crossbred with $M \times 1$-Cre recombinase transgenic (MxCre) floxed Pten mice. ${ }^{49,50}$ To induce Cre, animals were intraperitoneally injected with $100 \mu \mathrm{L}$ of polyinosine-polycytidine (plpC; $2 \mathrm{mg} / \mathrm{mL}$; Sigma Aldrich) at the age of 5 to 7 weeks on 3 consecutive days.

\section{Transplantation of FLCs}

Fetal liver cells (FLCs) were isolated from Stat $3 \beta^{T G}$ and wild-type (wt) mice at embryonic day 13.5, genotyped, and frozen in fetal bovine serum with $10 \%$ dimethyl sulfoxide. Platinum $E$ cells were transfected by calcium phosphate coprecipitation with the pMSCVMLL-AF9-IRES-Venus vector. FLCs were thawed 1 day before infection. Cells were spinoculated $(1000 \mathrm{~g}$ for 90 minutes) with retroviral supernatant in the presence of $10 \mu \mathrm{g} / \mathrm{mL}$ of polybrene (Sigma Aldrich). After 24 hours, $2 \times 10^{6} \mathrm{FLCs}$ were injected into immunocompromised NOD.Cg-Prkdc ${ }^{\text {scid }} / / 2 \mathrm{rg}^{\mathrm{tm} 1 \mathrm{Wjl}} / \mathrm{SzJ}$ (The Jackson Laboratory, Bar Harbor, ME) mice via the tail vein. Infection rates for MLL-AF9/Venus ${ }^{+}$(Venus $^{+}$) cells ranged from $7 \%$ to $12 \%$. Four weeks after transplantation, mice were injected with plpC, as described in "Animal studies."

\section{Statistics}

Patient data. STAT3 $\beta / \alpha$ messenger RNA (mRNA) ratio values were compared between groups using the Kruskal-Wallis test followed by pairwise comparisons corrected for multiplicity by Dunn's method. To test the association between the STAT3 $\beta$ / $\alpha$ mRNA ratio and survival of patients with $A M L$, a multivariable Cox regression model was used. In addition to the logSTAT3 $\beta$ / $\alpha$ ratio as a continuous variable, the model included and thus corrected for established AML risk parameters: patient age at diagnosis, percentage of blasts of all white blood cells (WBCs), and cytogenetic risk group as categorical predictor. To show the effect of logSTAT3 $\beta / \alpha$ ratio on the survival function, it was plotted once for the maximally observed ratio, once for the median, and once for the lowest observed ratio. To visualize the change in hazard ratio (HR) associated with a certain STAT3 $\beta / \alpha$ ratio change, it was calculated relative to the estimated survival at the median STAT3 $\beta / \alpha$ ratio using $\operatorname{Exp}(\mathrm{B})$ and its $95 \%$ confidence interval.

Animal and cellular data. Data were analyzed using logrank Student $t$ tests (Mantel Cox), Student $t$ tests, and 1-way analyses of variance in combination with Tukey's multiple comparison post hoc test. Error bars represent means \pm standard deviations. $P<.05$ was regarded as statistically significant. $P$ values are indicated as follows: ${ }^{\star} P<.05,{ }^{\star \star} P<.01$, and ${ }^{* \star *} P<.001$. The absence of a $P$ value or asterisk indicates nonsignificance. Additional methods are provided in the supplemental material. 


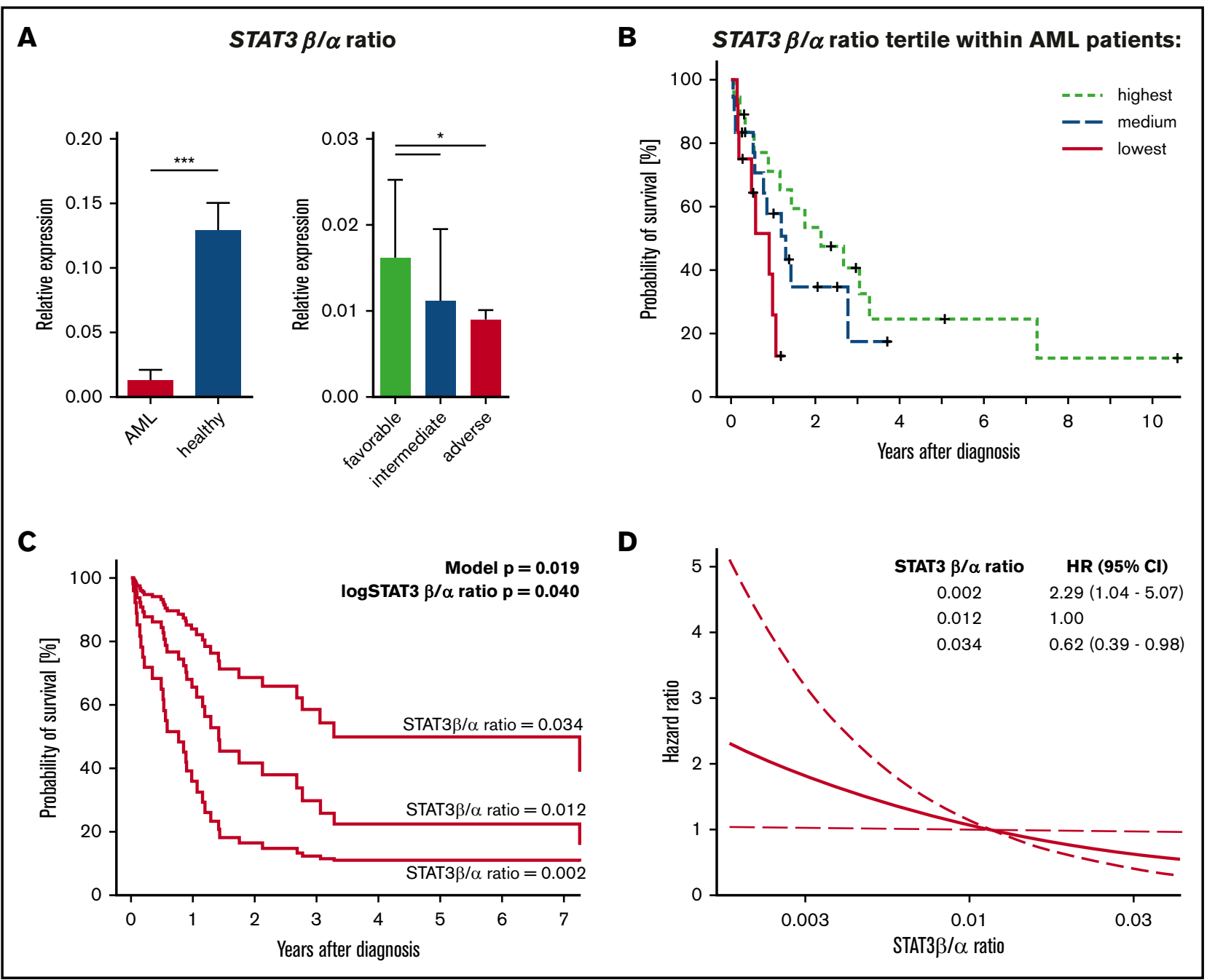

Figure 1. A higher STAT3 $\beta / \alpha$ mRNA ratio correlates with clinical prognosis and survival in AML patients. (A) STAT3 $\beta / \alpha$ mRNA ratio (normalized to $\beta$-ACTIN) in AML patients $(n=94)$ and HSPCs from healthy controls $(n=8)$, and STAT3 $\beta / \alpha$ mRNA ratio in AML patients with a favorable $(n=23)$, intermediate $(n=22)$, or adverse $(\mathrm{n}=49)$ prognosis. Data were compared using the Student $t$ test and Kruskal-Wallis test. (B) Kaplan-Meier plot showing the survival of patients with a STAT3 $\beta / \alpha$ mRNA ratio in the highest, medium, or lowest tertile $(n=48)$. (C) Estimated survival functions resulting from multivariable Cox regression. In addition to the logSTAT3 $\beta / \alpha$ mRNA ratio in its continuous form, the model includes and thus adjusts for patient age, blast count, and cytogenetic risk category at diagnosis. For illustrative purposes, curves were plotted for the maximal, median, and minimal observed STAT3 $/ \alpha$ mRNA ratios. The model $P$ value refers to the hypothesis that all variables in the model collectively predict survival; the $\operatorname{logSTAT3\beta /\alpha }$ mRNA $P$ value tests whether the ratio predicts survival independent of other variables. Of note, the estimated survival changes continuously with the STAT3 $\beta / \alpha$ mRNA ratio. Therefore, the survival can be plotted for any STAT3 $\beta / \alpha$ mRNA ratio value. To visualize the magnitude of survival difference between the maximally observed (0.034) and the minimally observed (0.002), we plotted survival function for these values and for the median value as reference. Modeling the effect of STAT3ß/ $\alpha$ mRNA ratio in its continuous form allowed avoidance of arbitrary groups. (D) Change of estimated HR (thick line) with $95 \%$ confidence interval (Cl; dashed lines) associated with different STAT3 $\beta / \alpha$ mRNA ratio levels. The median STAT3 $/ \alpha$ mRNA ratio was chosen as reference, not affecting the statistical analysis. The curve was plotted for a range of STAT3 $\beta / \alpha$ mRNA ratios spanning from the minimum to maximum observed ratio. Estimated HRs are given for the upper and lower ends of the curve. ${ }^{\star} P<.05,{ }^{* \star *} P<.001$.

\section{Results}

\section{Higher ratio of STAT3 $\beta / \alpha$ mRNA expression correlates with favorable clinical prognosis and prolonged survival in AML patients}

Differential expression of STAT3 isoforms has been observed in $\mathrm{AML}$ patients, but whether their role is of oncogenic or tumorsuppressive nature is incompletely understood. ${ }^{29-32}$ We obtained diagnostic samples from 94 AML patients (supplemental Table 1) and analyzed mRNA expression of STAT3 isoforms in comparison with HSPCs from 8 healthy donors. The mRNA expression of total STAT3, STAT3 $\alpha$, and especially STAT3 $\beta$ differed between leukemic blasts and healthy HSPCs. We found significantly decreased mRNA expression levels of STAT3 $\beta$ in AML samples compared with healthy HSPCs (supplemental Figure 1A). Next, patients of different cytogenetic risk groups were compared regarding STAT3 expression levels (supplemental Figure 1B). Strikingly, we found that the STAT3 $\beta / \alpha$ mRNA expression ratio in AML samples was significantly lower 


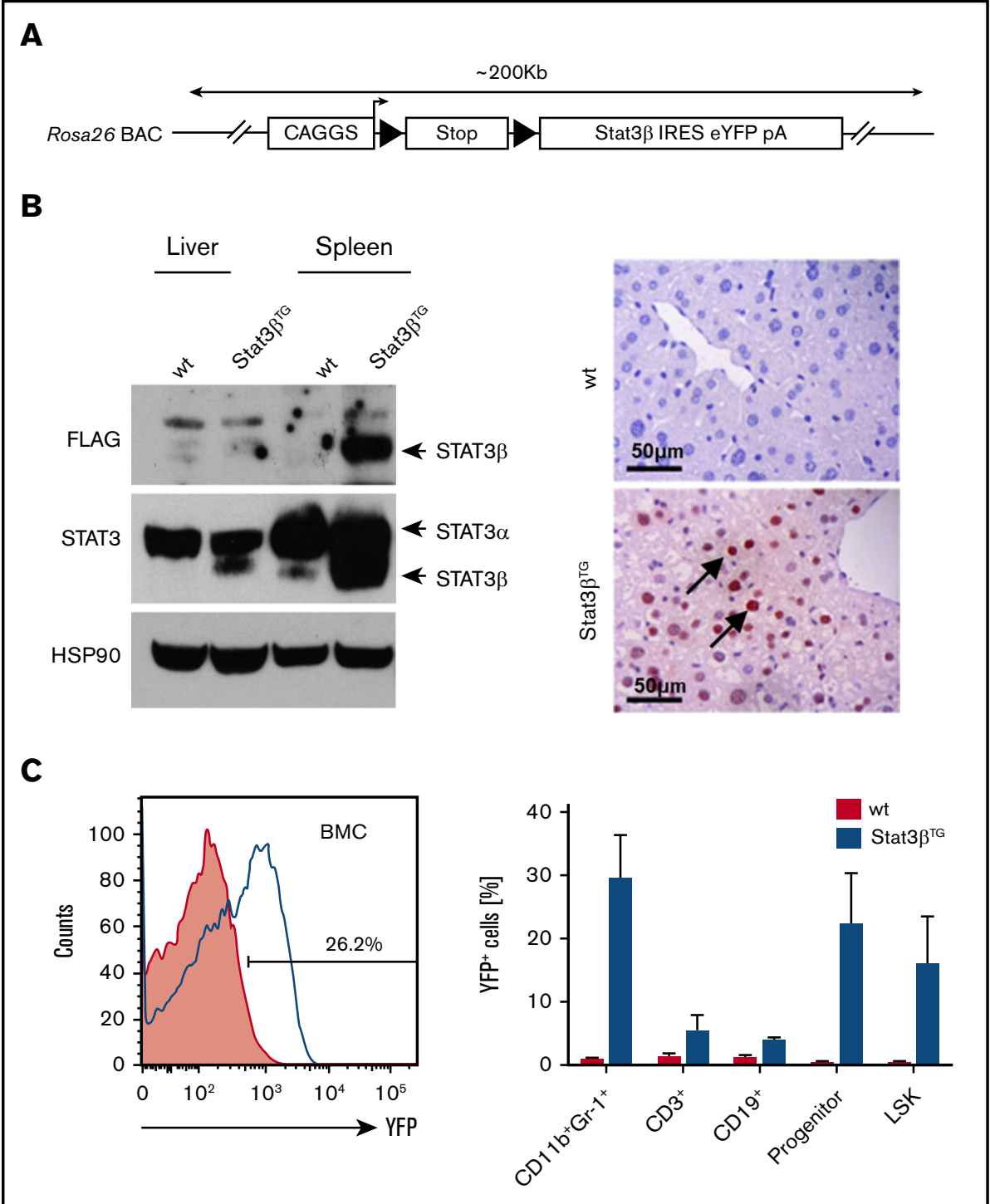

Figure 2. Generation and characterization of a Stat3 $\beta$ transgenic mouse model. (A) A schematic overview of the $S t a t 3 \beta$ transgene BAC construct. (B)

Total cell lysates from spleen and liver were subjected to western blot analysis with the indicated antibodies (STAT3, FLAG, and HSP90). Liver sections stained with an antibody against FLAG show the expression of ectopic STAT3 $\beta$. (C) A representative flow cytometry analysis of $\mathrm{YFP}^{+} \mathrm{BM}$ cells (BMCs) and hematopoietic cell populations (progenitor: $\mathrm{Lin}^{-} \mathrm{Sca}-1^{+} \mathrm{C}-\mathrm{Kit}^{-} ; \mathrm{LSK}$ : $\left.\mathrm{Lin}^{-} \mathrm{Sca}-1^{+} \mathrm{C}-\mathrm{Kit}^{+}\right)$at day 20 postinduction. Data (wt vs $\mathrm{Stat} 3 \beta^{\mathrm{TG}}$ ) were not statistically compared.

than that in healthy HSPCs and that a high STAT3 $\beta / \alpha$ mRNA ratio correlated with a favorable clinical prognosis (Figure $1 \mathrm{~A}$ ). Furthermore, we explored the correlation between the STAT3 $\beta$ / $\alpha$ mRNA ratio in AML patients $(n=48)$ and overall survival. $A$ higher $S T A T 3 \beta / \alpha$ mRNA ratio was associated with longer overall survival in AML patients (Figure 1B) after adjustment for patient age at diagnosis, percentage of blasts, and cytogenetic risk category (Figure $1 \mathrm{C}$ ). A 10 -fold increase of the STAT3 $\beta / \alpha$ mRNA ratio was estimated to be associated with an HR of 0.34 (95\% confidence interval, 0.12-0.95; Figure 1D). Taken together, the STAT3 $/ \alpha$ mRNA ratio correlates with clinical prognosis and survival in AML patients, arguing for the importance of strict maintenance of balanced STAT3 $\beta / \alpha$ mRNA expression.

\section{Generation and characterization of a novel Stat3 $\beta$ transgenic mouse model}

To investigate the role of STAT3 $\beta$, we established a novel mouse line conditionally expressing murine Stat $3 \beta$. We chose a BAC containing the Rosa26 locus, because this has been shown to be open chromatin and support transgene expression. The construct for the generation of Stat $3 \beta^{\mathrm{TG}}$ mice consisted of a CAGGS promoter followed by a floxed Stop cassette, FLAG-tagged murine Stat $3 \beta$ cDNA, and IRES and YFP (Figure 2A). Purified BAC DNA was microinjected into the pronucleus of C57BL/6 oocytes, and Stat $3 \beta^{T G}$ mice were identified via Southern blot and genotyping (supplemental Figure 2A). Conditional expression of the transgene was achieved by crossing Stat $3 \beta^{T G}$ mice with a plpCinducible MxCre mouse line on a C57BL/6 background. The resulting mice, heterozygous for $\mathrm{Cre}$ and the Stat $3 \beta$ transgene $\left(S t a t 3 \beta^{T G}\right)$, were injected with plpC, causing the expression of CRE recombinase and the excision of the Stop cassette and allowing for the expression of exogenous STAT3 $\beta$. Ectopic expression of STAT3 $\beta$ was confirmed in liver and spleen 20 days postinduction (Figure 2B). YFP was detected in $>20 \%$ of BMCs as well as in hematopoietic cell subsets (Figure 2C).

Stat $3 \beta^{T G}$ mice were found to be phenotypically normal before and after induced Stat $3 \beta^{\mathrm{TG}}$ expression (followed up to 12 months of life; data not shown). WBC count and relative spleen weight 
Figure 3. Elevated expression of STAT3 $\beta$ prolongs survival in plot showing the significantly different survival $(P=.0034)$ of $P_{t e n}{ }^{\Delta / \Delta}$ $(n=16)$ and Pten ${ }^{\Delta / \Delta}$ Stat $3 \beta^{\text {TG }}(n=11)$ mice, with $\operatorname{Pten}^{\Delta /+}(n=9)$ and $P_{t e n}{ }^{\Delta /+}$ Stat $3 \beta^{T G}(n=11)$ as controls. (B) Percentages of myeloid $\left(\mathrm{CD} 11 \mathrm{~b}^{+} \mathrm{Gr} 1^{+}\right)$and LSK cells in the BM and spleen of control, $\operatorname{Pten}^{\Delta / \Delta}$, and $\operatorname{Pten}^{\Delta / \Delta}$ Stat $3 \beta^{T G}$ mice at 10,20 , and 30 days postinduction ( $n=5$ per group). Data $\left(\operatorname{Pten}^{\Delta /+}\right.$ vs $\operatorname{Pten}^{\Delta / \Delta}$ vs $\operatorname{Pten}^{\Delta / \Delta}$ Stat $3 \beta^{T G}$ for each time point) were compared using 1-way analysis of variance. (C) H\&E-stained liver and spleen sections of $\operatorname{Pten}^{\Delta / \Delta}$, Pten ${ }^{\Delta / \Delta}$ Stat $3 \beta^{\top G}$, and control mice at day 20 postinduction. ${ }^{\star} P<.05,{ }^{\star \star} P<.01,{ }^{\star \star \star} P<.001$. an AML mouse model based on Pten deletion. (A) Kaplan-Meier

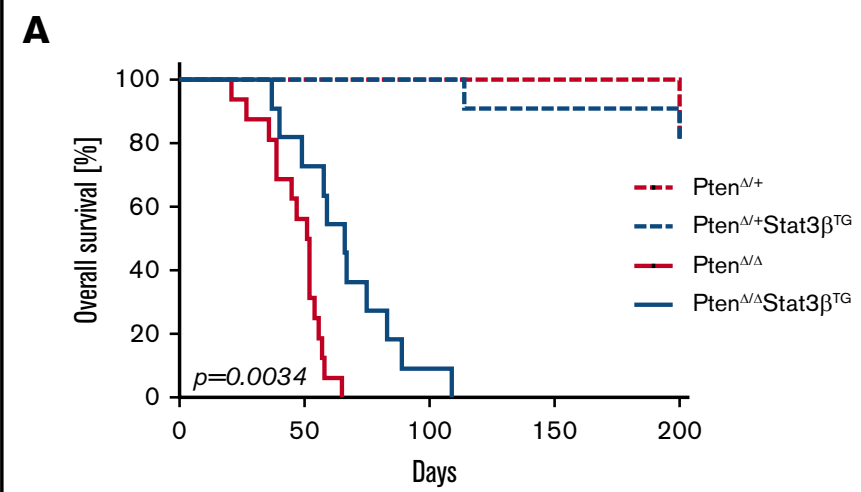

B
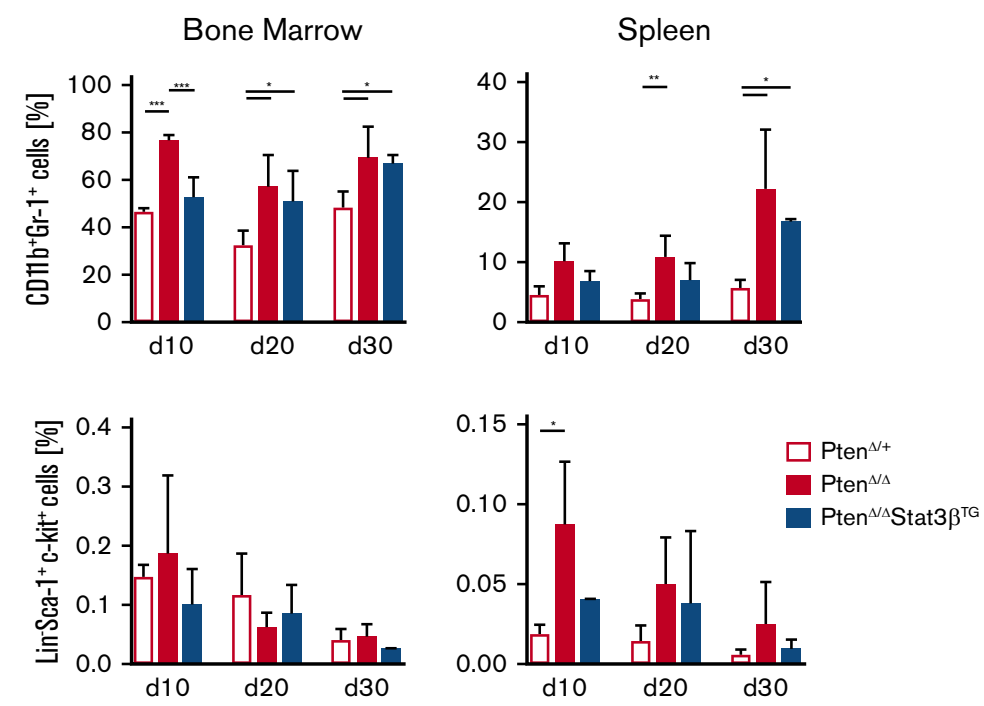

C
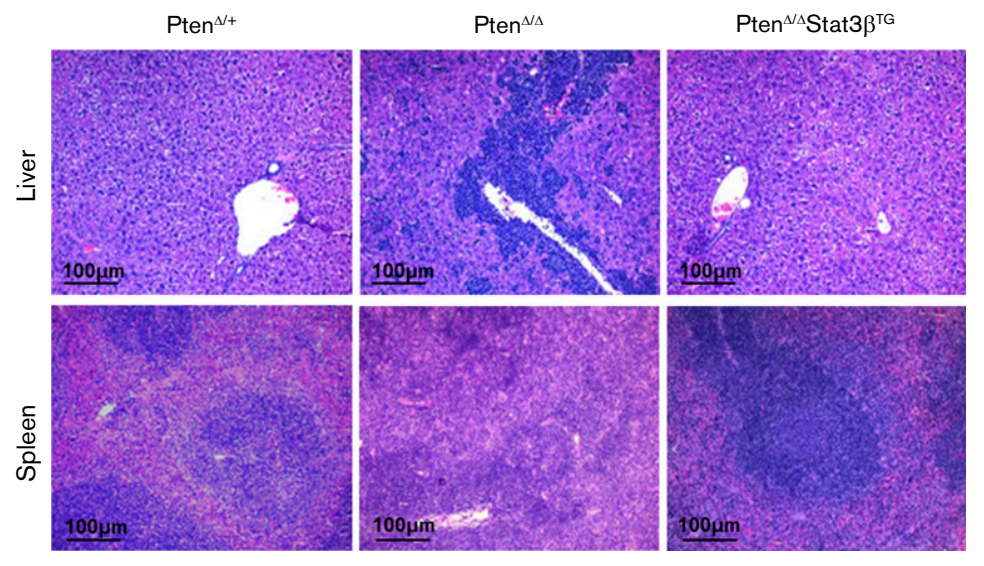

(normalized to body weight) in Stat $3 \beta^{\mathrm{TG}}$ mice were comparable to those of plpC-treated wt animals (supplemental Figure 2B). Furthermore, hematopoietic cell populations in BM and spleen were unaffected by $S t a t 3 \beta^{\mathrm{TG}}$ expression (supplemental Figure 2C). In accordance, hematoxylin and eosin (H\&E) staining of spleen and liver sections did not reveal any overt abnormalities in organ architecture or extramedullary hematopoiesis (supplemental Figure 2D).

\section{Elevated expression of STAT3 $\beta$ prolongs survival in an AML mouse model based on Pten deletion}

The impact of STAT3 $\beta$ on AML progression in vivo was investigated via the homozygous knockout of Pten in the hematopoietic compartment. Conditional ablation of Pten rapidly induces myeloproliferative neoplasms, which develop into secondary AML. ${ }^{49,50}$ 


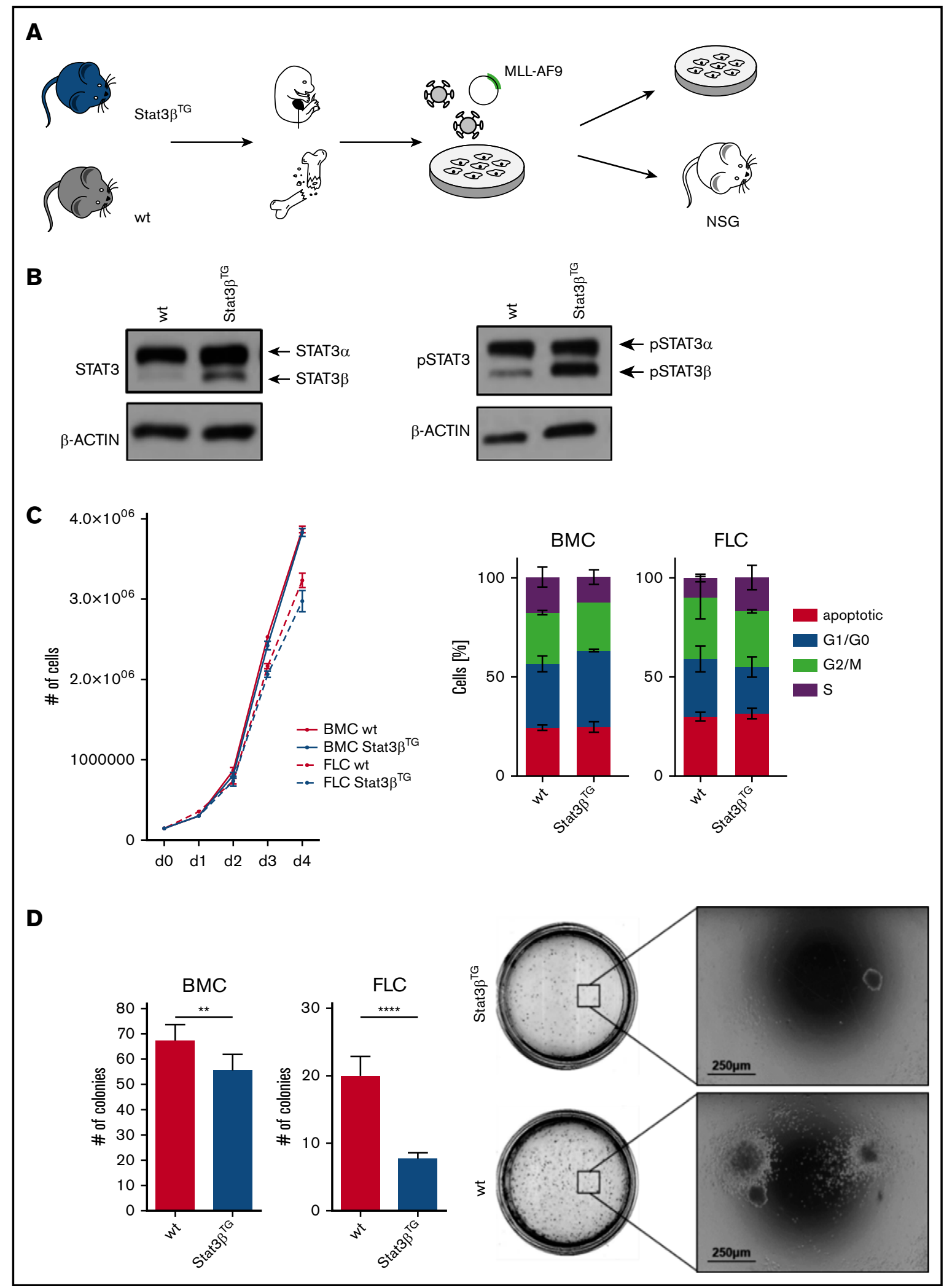

Figure 4. STAT3 $\beta$ impairs colony formation capacity of MLL-AF9-transformed cells. (A) Workflow of FLCs and BMCs harvested from Stat3 $\beta^{\text {TG }}$ mice and wt littermates. MLL-AF9-transformed cells were subsequently used for in vitro analysis and transplantation. (B) Western blot analysis showing STAT3 and phosphorylated STAT3 (pSTAT3) expression in FLCs transformed with MLL-AF9. Stat3 $\beta^{\text {TG }}$ expression was induced via stimulation with IFN $\beta$. (C) in vitro proliferation was analyzed via growth curves and cell cycle analysis by flow cytometry. Data, indicating 3 independent experiments carried out in triplicates, were compared using the Student $t$ test, and differences were 
Crossbreeding and plpC treatment gave rise to $\mathrm{MxCre}: \mathrm{Pten}^{\Delta /+}$, MxCre:Pten ${ }^{\Delta /+}:$ Stat3 $\beta^{T G}$, MxCre:Pten ${ }^{\Delta / \Delta}$, and MxCre:Pten ${ }^{\Delta / \Delta}$ : Stat $3 \beta^{\text {TG }}$ mice (MxCre is omitted in the annotation of mice hereafter). All mice with a homozygous ablation of Pten included in this study developed fatal myeloid leukemia within 110 days. Strikingly, we observed a significant increase in disease latency upon Stat $3 \beta^{T G}$ expression in $\mathrm{Pten}^{\Delta / \Delta}$ mice (Figure $3 \mathrm{~A}$ ). We detected elevated numbers of myeloid $\left(\mathrm{CD} 11 \mathrm{~b}^{+} \mathrm{Gr}-1^{+}\right)$cells in the BM and spleen of terminally ill Pten ${ }^{\Delta / \Delta}$ and $\operatorname{Pten}^{\Delta / \Delta}$ Stat $3 \beta^{T G}$ mice compared with $\mathrm{Pten}^{\Delta /+}$ control animals, consistent with an AML phenotype (supplemental Figure 3A). Although WBC count was strongly increased upon homozygous deletion of Pten, $\operatorname{Pten}^{\Delta / \Delta}$ Stat $3 \beta^{T G}$ mice exhibited a WBC count similar to that of healthy $\mathrm{Pten}^{\Delta /+}$ controls (supplemental Figure 3B).

To address the effect of STAT3 $\beta$ on leukemia progression, we analyzed mice at 3 different time points after plpC injection: days 10,20 , and 30 . We focused on the myeloid lineage as well as on HSPCs (defined as $\mathrm{Lin}^{-} \mathrm{Sca}-1^{+} \mathrm{c}-\mathrm{Kit}^{+}$[LSK]). Compared with $\mathrm{Pten}^{\Delta /+}$ control mice, Pten ${ }^{\Delta / \Delta}$ mice already exhibited an increase of myeloid cells in $\mathrm{BM}$ and spleen at day 10, which was delayed upon Stat $3 \beta^{T G}$ expression (Figure 3B top). Although the number of HSPCs in the BM remained relatively unchanged, Pten deletion caused a significant accumulation of HSPCs in the spleen, which was less pronounced in $\operatorname{Pten}^{\Delta / \Delta}$ Stat $3 \beta^{T G}$ mice (Figure 3B bottom). Analysis of H\&E-stained tissue sections from day 20 revealed reduced leukemic infiltration in liver and spleen of $\operatorname{Pten}^{\Delta / \Delta} \mathrm{Stat} 3 \beta^{\mathrm{TG}}$ compared with Pten ${ }^{\Delta / \Delta}$ mice (Figure $3 C$ ). Taken together, our data indicate that increased STAT3 $\beta$ levels impair leukemia progression and prolong disease latency in a Pten deletion-based AML mouse model.

\section{Stat $3 \beta^{\mathrm{TG}}$ expression impairs colony formation capacity of MLL-AF9-transformed cells}

The human fusion oncogene MLL-AF9 represents another widely used model for functional studies of AML. ${ }^{51,52}$ We harvested FLCs and BMCs from Stat $3 \beta^{T G}$ and wt mice and transduced them with a retrovirus encoding for MLL-AF9, coupled to the fluorescent protein Venus (Figure 4A). Before BM isolation, mice were treated with plpC to induce Stat $3 \beta^{T G}$ expression, whereas FLCs were treated with interferon $\beta$ (IFN $\beta$ ) in vitro to activate the $M \times 1$ promoter and express ectopic STAT3 $\beta$ (Figure 4B). As a control, all wt mice and FLCs were similarly treated with plpC or IFN $\beta$, respectively. Of note, expression of total and phosphorylated STAT $3 \alpha$ seemed unaffected by the expression of Stat $3 \beta^{T G}$ (Figure 4B). Homogeneous Venus ${ }^{+}$cell populations were used for all further in vitro experiments (supplemental Figure 4A). Proliferation kinetics of MLL-AF9-transformed cells were not altered between Stat $3 \beta^{T G}$ and wt cells (Figure $4 C$ ). Furthermore, mRNA levels of prominent STAT $3 \alpha$-regulated genes involved in cell proliferation remained unchanged in Venus $^{+}$Stat $3 \beta^{T G}$ and wt FLCs (supplemental Figure 4B). However, in methylcellulose-based colony formation assays, the expression of $S t a t 3 \beta^{T G}$ led to significantly reduced numbers of colonies for BMCs as well as FLCs (Figure 4D left) upon serial replating (supplemental Figure $4 \mathrm{C}$ ). In addition, colony sizes were slightly reduced in Stat3 $\beta^{T G}$ cells (Figure 4D right). Altogether, this indicates that Stat $3 \beta^{\mathrm{TG}}$ expression has no effect on STAT3 $\alpha$ activity or proliferation but impairs the cellular capacity for self-renewal, colony formation, and tumorigenicity of MLL-AF9-transformed cells.

\section{STAT3 $\beta$ has a tumor-suppressive effect in an MLL-AF9-dependent AML model}

MLL-AF9-transformed Stat $3 \beta^{\text {TG }}$ and wt FLCs were compared in an in vivo transplantation AML model. Transduced cells were injected into immunocompromised NOD.Cg-Prkdc ${ }^{\text {scid }} \| 2 \mathrm{rg}^{\mathrm{tm} 1 \mathrm{~W}_{\mathrm{jl}} /}$ SzJ (NSG) mice, and 4 weeks later, mice were treated with plpC to induce Stat $3 \beta^{T G}$ expression. We confirmed Stat $3 \beta^{T G}$ expression and phosphorylation with a FLAG-specific antibody and western blot (supplemental Figure 5A-B). Additionally, we investigated the mRNA expression of total Stat3 and both alternatively spliced isoforms (supplemental Figure 5C). Taken together, these data confirm the increased expression of STAT3 $\beta$ resulting from the transgene in vivo posttransplantation and furthermore demonstrate the unaffected expression and activation of STAT3 $\alpha$. As observed in the Pten model, transgenic Stat3 $\beta$ expression caused an increase in survival of mice in comparison with mice receiving wt cells in the MLL-AF9 model (Figure 5A). Immunophenotyping of Venus ${ }^{+}$blasts in PB and BM revealed high expression levels of the myeloid marker CD11b together with low to intermediate expression levels of c-kit (supplemental Figure 5D). Clear signs of leukemic infiltration in liver, spleen, and PB were found in both experimental groups at the time of euthanasia (supplemental Figure 6A).

To investigate the effect of STAT3 $\beta$ on MLL-AF9-driven leukemia progression, we analyzed mice 6 weeks posttransplantation. Here, the delayed disease phenotype in Stat $3 \beta^{T G}$ mice was evident in direct comparison; WBC count and relative spleen weight and size were reduced in the Stat $3 \beta^{T G}$ group (Figure 5B). Numbers of myeloid Venus ${ }^{+}$blasts were notably lower in PB, $\mathrm{BM}$, and spleen of Stat $3 \beta^{\mathrm{TG}}$ mice (Figure $5 \mathrm{C}$ ). H\&E-stained tissue sections demonstrated significantly decreased infiltration in liver and spleen and diminished numbers of blasts in PB smears (Figure 5D). In accordance with our previous observations, these results show that the elevated expression of STAT $3 \beta$ delays disease progression and the leukemic infiltration of peripheral hematopoietic organs, explaining the demonstrated survival advantage in $\mathrm{Stat} 3 \beta^{T G}$ mice.

Next, we addressed proliferation and apoptosis in the MLLAF9-dependent AML model. Neither in quantification of Ki67 ${ }^{+}$ cells (supplemental Figure 6B) nor in cell cycle analysis of Venus $^{+}$spleen-derived blasts did we observe a significant difference in proliferation (supplemental Figure 6C). Spleen and liver sections stained for cleaved caspase 3 demonstrated similarly low levels of apoptosis in both groups (supplemental Figure 6D), which was confirmed by annexin $V$ staining of

Figure 4. (continued) found not to be statistically significant. (D) Methylcellulose-based colony formation assays were analyzed by number of colonies upon 4 replatings (1 replating shown; $\mathrm{n}=12$ per group). Representative pictures of BMC colonies are shown. Data, indicating 2 independent experiments, were compared using the Student $t$ test. ${ }^{* \star} P<.01,{ }^{* * \star} P<.0001$. NSG, NOD.Cg-Prkdc ${ }^{\text {scid }} \| 2 \mathrm{rg}^{\text {tm } 1 \mathrm{~W}_{\mathrm{j}} /} / \mathrm{SzJ}$. 


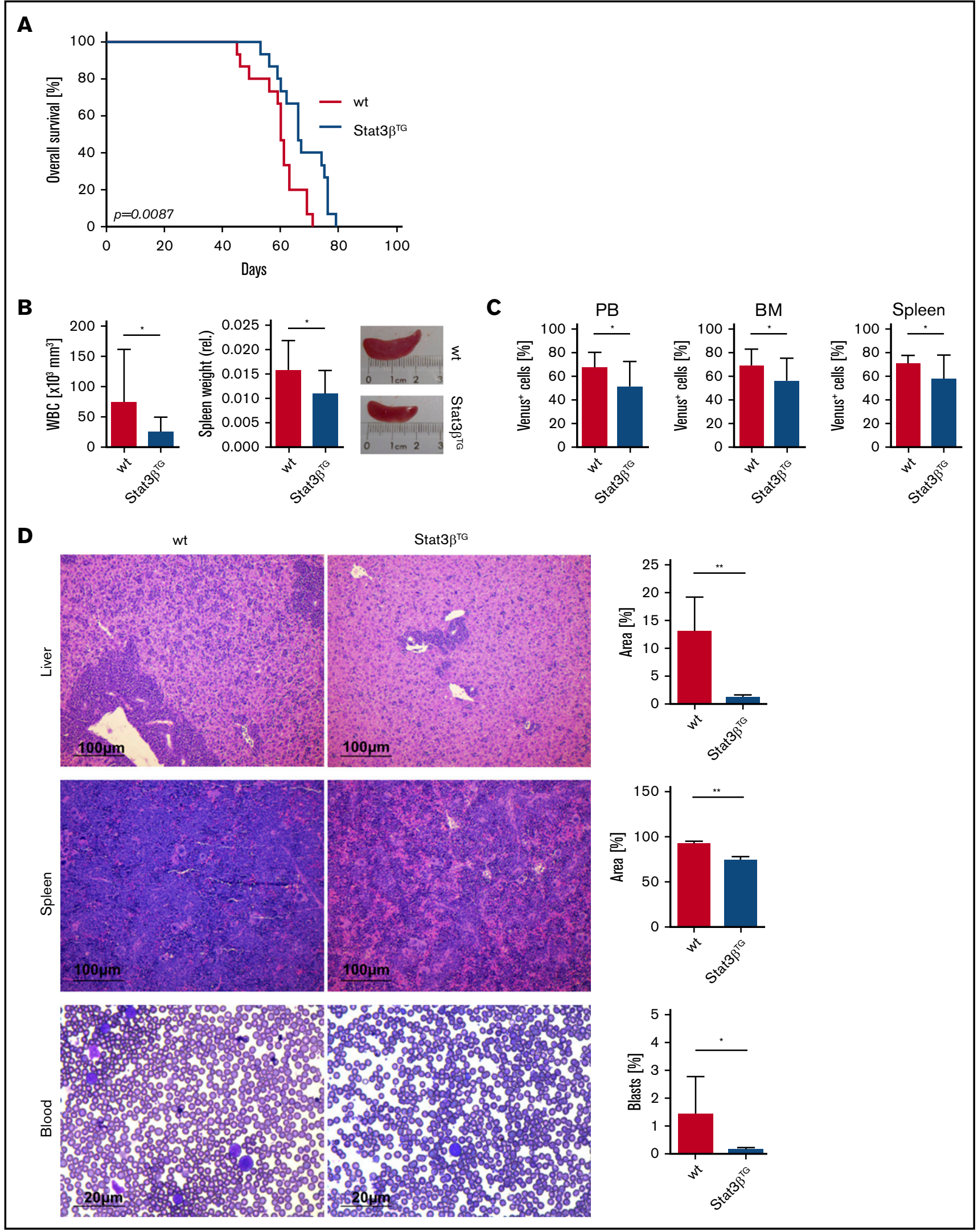

Figure 5. STAT3 $\beta$ prolongs survival and has a tumor-suppressive effect in MLL-AF9-dependent AML 6 weeks posttransplantation. (A) Kaplan-Meier plot of NOD.Cg-Prkdc ${ }^{\text {scid }} / 2 \mathrm{rg}^{\text {tm } 1 \mathrm{~W}_{\mathrm{j}} / \mathrm{SzJ}}$ (NSG) mice receiving transplants of Stat $3 \beta^{\mathrm{TG}}$ and wt FLCs ( $\mathrm{n}=15$ per group), showing significantly different survival ( $P=.0087$ ). (B) WBC 
blasts derived from PB, BM, liver, and spleen (supplemental Figure $6 \mathrm{E}$ ). Thus, the antitumorigenic function of STAT3 $\beta$ seems to be independent of the direct regulation of apoptosis or proliferation.

\section{Gene expression patterns of migratory target genes change upon increased STAT3 $\beta$ expression}

To identify Stat $3 \beta^{T G}$-induced global changes in gene expression in MLL-AF9-driven leukemia, we performed RNA sequencing of sorted Venus ${ }^{+}$BMCs harvested from mice 6 weeks posttransplantation. We analyzed 3 animals per group and found 70 genes that were significantly up- (32 genes) or downregulated (38 genes) upon Stat $3 \beta^{\mathrm{TG}}$ expression (Figure 6A). Gene set enrichment analysis revealed enriched expression of genes in the interleukin 6 (IL6)/JAK/STAT3 signaling pathway in Stat $3 \beta^{T G}$ blasts (supplemental Figure $7 \mathrm{~A}$ ). Furthermore, genes allocated to Reactome pathways of cell surface interactions at the vascular wall were significantly upregulated, including Sell, Itgax, and Cd177 (supplemental Figure 7B). The surface molecule SELL (L-SELECTIN, CD62L) represents an interesting target due to its role in lymphocyte migration through vasculature, because a downregulation of SELL on lymphocytes or leukemic blasts can initiate cell migration from the BM into the PB, where it is shed. ${ }^{53-56}$ Expression of Sell was significantly upregulated in Stat $3 \beta^{T G}$ blasts at the mRNA level (Figure $6 \mathrm{~B}$ top). We confirmed the Stat $3 \beta^{T G_{-}}$-specific upregulation of SELL in vivo on BM-derived $\mathrm{Venus}^{+}$blasts via flow cytometry (Figure 6B middle). Additionally, we measured soluble, shed SELL in the plasma and detected decreased levels in mice receiving Stat $3 \beta^{\mathrm{TG}}$ cell transplants (Figure 6B bottom), indicating that Stat $3 \beta^{T G}$ blasts migrate in lower numbers in comparison with wt. This is in accordance with our in vivo findings, which demonstrated a significantly reduced organ infiltration and blast count in the PB of the Stat $3 \beta^{\mathrm{TG}}$ group. Lastly, we repeated the methylcellulose-based colony formation assays with BMCs and FLCs that were previously treated with a blocking antibody for cell surface-bound SELL/ CD62L. Indeed, the antibody-mediated blocking of SELL reversed the effect of $S$ tat $3 \beta^{\mathrm{TG}}$ expression (Figure $6 \mathrm{C}$ ) upon serial replating (supplemental Figure $7 \mathrm{C}$ ). As a control, we analyzed the blocking efficiency via flow cytometry (supplemental Figure 7D). In addition, we used publicly available data to identify STAT3-specific binding motifs in the Sell promoter (supplemental Figure 8A). Analysis of published chromatin immunoprecipitation sequencing data sets from human and mouse samples confirmed multiple STAT3 binding events in regions across the gene (supplemental Figure $8 \mathrm{~B}$ ). In summary, these data show that STAT3 $\beta$ can promote target gene induction and actively influence the expression of cell surface markers in MLL-AF9-expressing blasts involved in vascular interaction and migration. Among those markers, SELL might play a distinct role in the antitumorigenic effect of $S t a t 3 \beta^{T G}$ in AML cells.

\section{Increased levels of SELL correlate with favorable clinical prognosis and increased event-free survival in AML patients}

Finally, we investigated SELL expression in our AML cohort of favorable, intermediate, and adverse prognostic groups and found elevated mRNA levels of SELL in patients with a favorable prognosis, which was associated with a higher STAT3 $\beta / \alpha$ mRNA ratio (Figure 7A). Accordingly, we also found elevated levels of SELL/CD62L in samples derived from patients with a favorable prognosis measured via flow cytometry (Figure 7B). Using 3 of the identified STAT3 $\beta$-regulated gene targets involved in cell migration (SELL, ITGAX, CD177) as a STAT3 $\beta$ gene signature and a publicly available AML patient data set $(n=740)$, we were able to show an association between high expression of the STAT3 $\beta$ signature and prolonged event-free survival ( $\mathrm{HR}, 0.78 ; P=.033$; Figure $7 \mathrm{C})$. In conclusion, these data suggest that STAT3 $\beta$-dependent elevated SELL expression correlates with a favorable outcome in AML patients.

\section{Discussion}

STAT3 is frequently found to be constitutively active in AML. ${ }^{25-27}$ We were able to demonstrate a low $S T A T 3 \beta / \alpha$ mRNA ratio in AML cells in comparison with healthy HSPCs as well as a high $S T A T 3 \beta / \alpha$ mRNA ratio in patients with a favorable cytogenetic prognosis. Moreover, a lower STAT3 $/ \alpha$ mRNA ratio was associated with higher overall mortality. Notably, this relationship persists despite correction for established prognostic factors, such as cytogenetic risk category, age, and percentage of blasts at diagnosis. Although these results need to be verified in larger confirmatory studies, they are especially plausible in light of the mechanistic insight gained from our animal experiments, pointing to a central role of STAT3 $\beta$ in AML. Intriguingly, findings are similar to the described STAT3 $\beta$ function in esophageal squamous cell carcinoma patients, where it was established as a protective prognostic marker. ${ }^{17}$

Here, we describe a novel tumor-suppressive role for STAT3 $\beta$ in AML. Evidence was provided from an inducible Stat $\beta \beta$ transgenic mouse model in combination with 2 independent drivers for AML, either MLL-AF9 expression or PTEN deficiency. We demonstrated that $S$ tat $3 \beta^{T G}$ expression in $A M L$ blasts significantly extended survival by delaying infiltration of $P B$ and hematopoietic organs, which is characteristic for AML. Our data further suggest that the antitumorigenic effect of STAT3 $\beta$ depends on the tumor-intrinsic regulation of a small set of significantly regulated genes. Several genes of the IL6/JAK/ STAT3 signaling pathway and the Reactome pathway for cell surface interactions at the vascular wall were upregulated in Stat $3 \beta^{\text {TG }}$ blasts, demonstrating that STAT3 $\beta$ can actively regulate gene expression. ${ }^{11,13-16}$ SELL was identified as a target gene of interest, because it was shown to be specifically upregulated in Stat $3 \beta^{\mathrm{TG}}$ blasts and is known to be expressed in newly diagnosed AML patients. ${ }^{57-61}$ In particular,

Figure 5. (continued) count and relative spleen weight and size. (C) Quantification by flow cytometry of myeloid Venus ${ }^{+}$blasts in $\mathrm{PB}, \mathrm{BM}$, and spleen of $\mathrm{Stat} 3 \beta^{\mathrm{TG}}$ and $\mathrm{wt}$ mice. (D) H\&E-stained liver and spleen sections and PB smears of wt and Stat $3 \beta^{T G}$ animals. Quantifications shown as infiltrate area/total organ area (\%) and number of blasts/ total cell number (\%). (B-D) Data were compared using the Student $t$ test. ${ }^{\star} P<.05,{ }^{\star \star} P<.01$. 


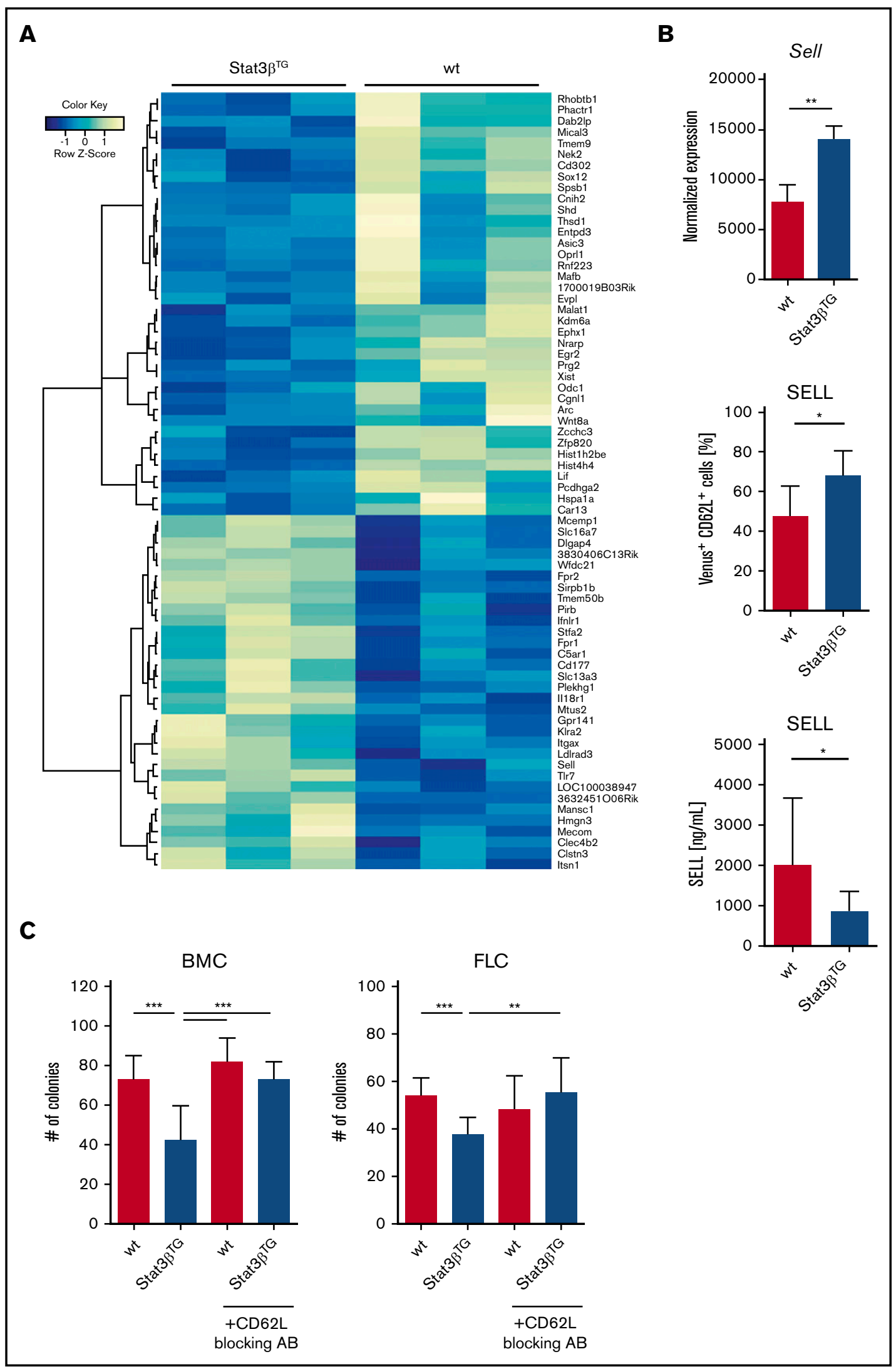

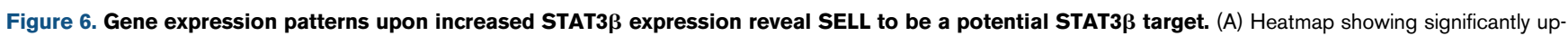
(32 genes) or downregulated (38 genes) genes between murine wt and $\mathrm{Stat} 3 \beta^{\mathrm{TG}}$ BM-derived Venus ${ }^{+}$blasts $(n=3)$. (B) Normalized mRNA expression, displaying the 


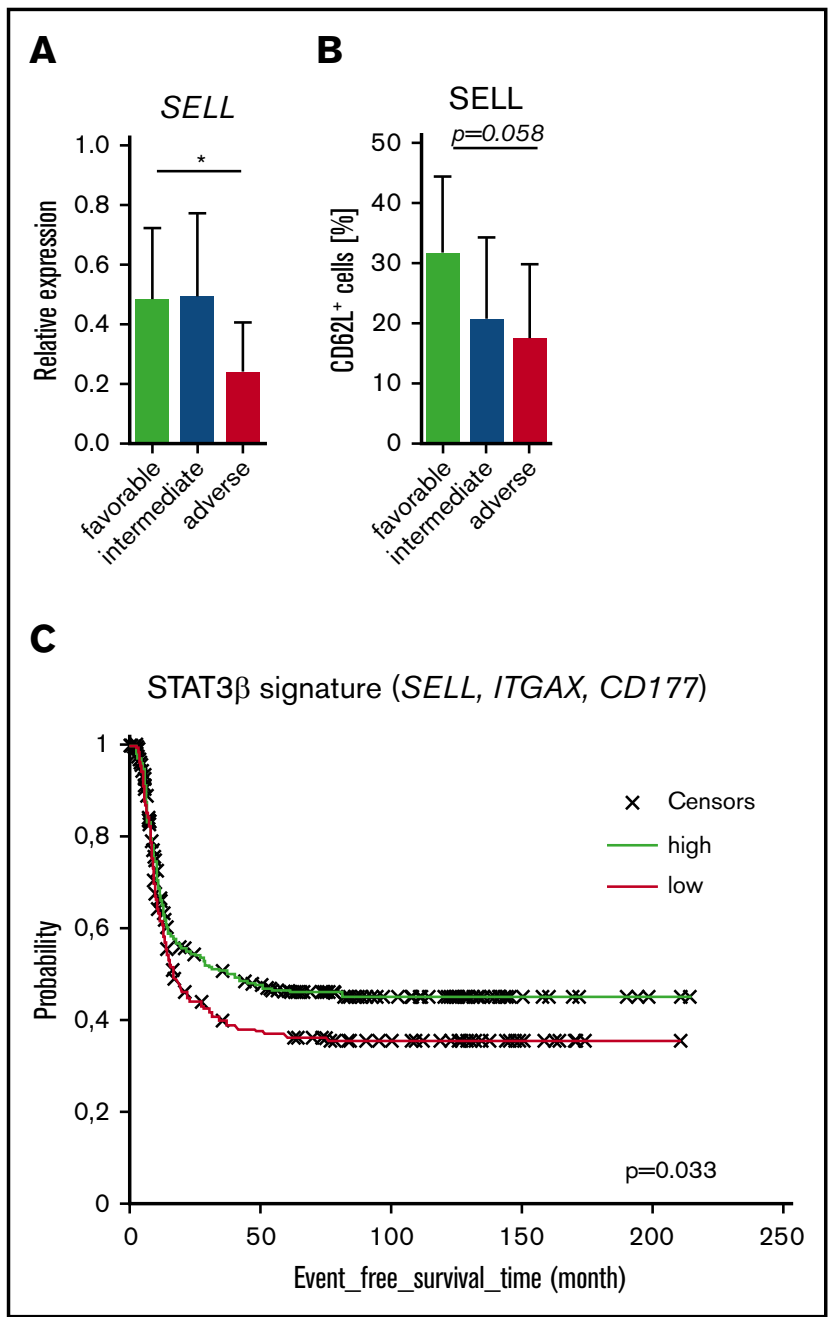

Figure 7. Increased levels of SELL correlate with favorable clinical prognosis in our AML cohort and increased event-free survival in publicly available AML patient data sets. (A) SELL mRNA expression levels (normalized to $\beta$-ACTIM) in AML patients with favorable $(n=9)$, intermediate $(n=38)$, or adverse $(\mathrm{n}=8)$ prognosis. Data (favorable vs adverse) were compared using the Student $t$ test. (B) SELL/CD62L expression levels analyzed by flow cytometry in AML blasts from patients with favorable $(n=7)$, intermediate $(n=38)$, or adverse $(n=7)$ prognosis. Data (favorable vs adverse) were compared using the Student $t$ test, and significance is indicated by $P=.058$. (C) Gene signatures from publicly available AML patient data sets $(n=740)$ were compared, showing that patients with high expression of the STAT3 $\beta$ signature (SELL, ITGAX, CD177) had better survival compared with patients with low expression in $740 \mathrm{AML}$ patients (HR, 0.78; $P=.33$ ). ${ }^{\star} P<.05$.

SELL is important for the homing of AML cells, because its downregulation could initiate the mobilization of AML blasts from the $B M$ into the PB, where it is shed and remains in the PB in its soluble form. ${ }^{53-56}$ In our MLL-AF9-based AML in vivo model, SELL was specifically upregulated in Stat $3 \beta^{T G} B M-r e s i d e n t$ AML blasts at the mRNA and protein levels in comparison with wt. This explains the delayed peripheral infiltration of Stat $3 \beta^{\mathrm{TG}}$ blasts and the consequent suspension of disease progression. In line with this, levels of shed SELL in the PB were significantly reduced in mice receiving Stat $3 \beta^{\mathrm{TG}}$ cells, indicating a clear reduction in AML cell mobilization.

SELL expression on hematopoietic progenitors in vitro has been described to correlate with their clonogenic potential. ${ }^{62}$ Likewise, we found the capacity of transformed BMCs and FLCs for in vitro colony formation to be impaired upon Stat $3 \beta^{\mathrm{TG}}$ expression, which was preventable with antibody-mediated blocking of SELL. Together, these findings indicate that the antitumorigenic effect of Stat $3 \beta^{T G}$ expression in AML cells might be at least partially dependent on the upregulation of SELL. However, because the colony formation capacity of HSPCs and AML cells considerably depends on STAT3 activity, ${ }^{28,63}$ STAT3 $\beta$ might also counteract STAT3 and therefore reduce colony formation. Because of its unique C-terminus, STAT3 $\beta$ homodimers have been demonstrated to exhibit prolonged phosphorylation and nuclear retention ${ }^{64}$ as well as enhanced DNA-binding affinity ${ }^{16,65}$ and dimer stability. ${ }^{65}$ Thus, STAT3 $\beta$ can directly compete with STAT3 $\alpha$ and furthermore regulate STAT $3 \alpha$ via the formation of heterodimers. ${ }^{15,17}$ Nevertheless, we failed to obtain any evidence suggesting a negative regulation of STAT3 $\alpha$ by STAT3 $\beta$ in AML. In fact, we found the activity of STAT3 $\alpha$ and STAT3 $\alpha$-regulated genes in AML blasts to be unaffected by the expression of $\operatorname{Stat} 3 \beta^{\mathrm{TG}}$, which is similar to previous findings. ${ }^{11}$

In AML patients, increased SELL expression was reported to correlate with good-risk karyotypes. ${ }^{66}$ Accordingly, we found SELL levels to be significantly elevated in patients with a favorable prognosis, in contrast to patients with an adverse prognosis. Furthermore, analysis of publicly available AML data sets revealed a correlation between high expressions of newly identified STAT3 $\beta$-regulated migratory genes (SELL, ITGAX, CD177) and superior event-free survival. In addition to Sell, Itgax, and CD177, we identified other novel STAT3 $\beta$-regulated genes, such as Lif, Sox12, Mafb, and Ifn/r1, that might also contribute to the tumorsuppressive effect of STAT3 $\beta$ but whose specific role in AML remains elusive. Taken together, the exact mechanism underlying the tumor-suppressive function of STAT3 $\beta$ is most likely a combination of various regulated genes, such as Sell, and deserves further investigation.

In summary, our study unequivocally demonstrates that STAT3 $\beta$ acts as a tumor suppressor in AML and specifically regulates gene expression in AML blasts, impairing leukemia progression and extending survival.

Figure 6. (continued) upregulation of Sell in Venus ${ }^{+}$Stat $3 \beta^{T G}$ blasts, is shown (top; $n=3$ per group). Quantification of cell surface-bound SELL/CD62L in BM-derived Venus $^{+}$blasts, measured by flow cytometry (middle; $\mathrm{n}=6$ per group), and levels of soluble, shed SELL in plasma, assessed via enzyme-linked immunosorbent assay (bottom; $n=9$ per group), demonstrate the upregulation of SELL on the cell surface of Stat $3 \beta^{T G}$ blasts and the difference in shed SELL present in PB. Data were compared using the Student $t$ test. (C) Methylcellulose-based colony formation assays of wt and Stat3 $\beta^{\mathrm{TG}} \mathrm{FLCs}$ and BMCs, pretreated with or without a blocking antibody for SELL/CD62L (MEL-14), were analyzed by number of colonies upon 3 replatings ( 1 replating shown; $n=12$ per group). Data were compared using 1 -way analysis of variance. ${ }^{\star} P<.05$, ${ }^{\star *} P<.01,{ }^{* \star \star} P<.001$. 


\section{Acknowledgments}

The authors thank J. Zuber (Research Institute of Molecular Pathology, Vienna, Austria) for the pMSCV-MLL-AF9-IRES-Venus construct as well as S. Höger, M. Schlederer, S. Zahma, and J. Mohrherr for their help and expertise in immunohistochemistry. The authors also thank C. Bock (Research Center for Molecular Medicine, Vienna, Austria) and the Biomedical Sequencing Facility. The authors are grateful to V. Sexl, B. Strobl, and M. Müller for helpful discussions. O. Sharif, V. Greß, A. Elkasaby, and S. Edtmayer provided further support.

The position of P.A. is funded by the Children's Cancer Research Institute, Vienna, Austria. Financial support was further provided by Marie Curie International Incoming Fellowship CMLMULTIHIT (\#254408) (T.M.), Austrian Science Fund (FWF) grants \#SFBF4707-B20 and \#SFB-F6105 (R.M.), FWF grant \#P25599 (E.C.), and European Research Council Starting Grant ONCOMECHAML (\#636855/StG) (F.G. and T.E.).

P.A. is a PhD candidate at the Medical University of Vienna, and this work is submitted in partial fulfillment of the requirement for a $\mathrm{PhD}$.

\section{Authorship}

Contribution: P.A., T.M., E.C., and D.S. designed research; P.A. and T.M. performed experiments and analyzed data; E.C., J.H., V.J., S.H., T.E., H.P.M., A.Y., L.K., and B.G. performed and analyzed additional experiments; H.S., K.L., M.J.M.F., F.G., R.M., and E.C. provided essential material and discussion; P.A. and D.S. wrote the manuscript; and all authors approved the manuscript.

Conflict-of-interest disclosure: The authors declare no competing financial interests.

ORCID profiles: T.E., 0000-0002-0932-2052; S.H., 00000002-3398-0442; H.P.M., 0000-0001-6438-9068; A.Y., 00000001-9638-4026; L.K., 0000-0003-2184-1338; F.G., 0000-00034289-2281; R.M., 0000-0003-0918-9463; E.C., 0000-00017992-5361; D.S., 0000-0002-8824-0767.

Correspondence: Dagmar Stoiber, Division of Pharmacology, Department Pharmacology, Physiology and Microbiology, Karl Landsteiner University of Health Sciences, Dr.-Karl-Dorrek-Str 30, 3500 Krems, Austria; e-mail: dagmar.stoiber@kl.ac.at.

\section{References}

1. Avalle L, Pensa S, Regis G, Novelli F, Poli V. STAT1 and STAT3 in tumorigenesis: a matter of balance. JAKSTAT. 2012;1(2):65-72.

2. Alonzi T, Newton IP, Bryce PJ, et al. Induced somatic inactivation of STAT3 in mice triggers the development of a fulminant form of enterocolitis. Cytokine. $2004 ; 26(2): 45-56$.

3. Yu H, Lee H, Herrmann A, Buettner R, Jove R. Revisiting STAT3 signalling in cancer: new and unexpected biological functions. Nat Rev Cancer. 2014; 14(11):736-746.

4. Yuan J, Zhang F, Niu R. Multiple regulation pathways and pivotal biological functions of STAT3 in cancer. Sci Rep. 2015;5:17663.

5. Yeh JE, Frank DA. STAT3-interacting proteins as modulators of transcription factor function: implications to targeted cancer therapy. ChemMedChem. 2016;11(8):795-801.

6. Poli V, Camporeale A. STAT3-mediated metabolic reprograming in cellular transformation and implications for drug resistance. Front Oncol. $2015 ; 5: 121$.

7. Zhang H-F, Lai R. STAT3 in cancer-friend or foe? Cancers (Basel). 2014;6(3):1408-1440.

8. Avalle L, Camporeale A, Camperi A, Poli V. STAT3 in cancer: a double edged sword. Cytokine. 2017;98:42-50.

9. Dewilde S, Vercelli A, Chiarle R, Poli V. Of alphas and betas: distinct and overlapping functions of STAT3 isoforms. Front Biosci. 2008;13:6501-6514.

10. Shao H, Quintero AJ, Tweardy DJ. Identification and characterization of cis elements in the STAT3 gene regulating STAT3 alpha and STAT3 beta messenger RNA splicing. Blood. 2001;98(13):3853-3856.

11. Maritano D, Sugrue ML, Tininini S, et al. The STAT3 isoforms $\alpha$ and $\beta$ have unique and specific functions. Nat Immunol. 2004;5(4):401-409.

12. Wen Z, Zhong Z, Darnell JE Jr. Maximal activation of transcription by Stat1 and Stat3 requires both tyrosine and serine phosphorylation. Cell. 1995; 82(2):241-250.

13. Caldenhoven E, van Dijk TB, Solari R, et al. STAT3beta, a splice variant of transcription factor STAT3, is a dominant negative regulator of transcription. J Biol Chem. 1996;271(22):13221-13227.

14. Alonzi T, Maritano D, Gorgoni B, Rizzuto G, Libert C, Poli V. Essential role of STAT3 in the control of the acute-phase response as revealed by inducible gene inactivation [correction of activation] in the liver [published correction appears in Mol Cell Biol. 2001;21 (8):2967]. Mol Cell Biol. 2001;21(5): 1621-1632.

15. $\mathrm{Ng} \mathrm{IH}, \mathrm{Ng} \mathrm{DC}$, Jans DA, Bogoyevitch MA. Selective STAT3- $\alpha$ or $-\beta$ expression reveals spliceform-specific phosphorylation kinetics, nuclear retention and distinct gene expression outcomes. Biochem J. 2012;447(1):125-136.

16. Schaefer TS, Sanders LK, Park OK, Nathans D. Functional differences between Stat3alpha and Stat3beta. Mol Cell Biol. 1997;17(9):5307-5316.

17. Zhang HF, Chen $\mathrm{Y}, \mathrm{Wu} \mathrm{C}$, et al. The opposing function of STAT3 as an oncoprotein and tumor suppressor is dictated by the expression status of STAT3 $\beta$ in esophageal squamous cell carcinoma. Clin Cancer Res. 2016;22(3):691-703.

18. Zammarchi F, de Stanchina E, Bournazou E, et al. Antitumorigenic potential of STAT3 alternative splicing modulation. Proc Natl Acad Sci USA. 2011; 108(43):17779-17784.

19. Ivanov VN, Zhou H, Partridge MA, Hei TK. Inhibition of ataxia telangiectasia mutated kinase activity enhances TRAIL-mediated apoptosis in human melanoma cells. Cancer Res. 2009;69(8):3510-3519. 
20. Niu G, Shain $\mathrm{KH}$, Huang M, et al. Overexpression of a dominant-negative signal transducer and activator of transcription 3 variant in tumor cells leads to production of soluble factors that induce apoptosis and cell cycle arrest. Cancer Res. 2001;61 (8):3276-3280.

21. Xu G, Zhang C, Zhang J. Dominant negative STAT3 suppresses the growth and invasion capability of human lung cancer cells. Mol Med Rep. 2009;2(5): 819-824.

22. Niu G, Heller R, Catlett-Falcone R, et al. Gene therapy with dominant-negative Stat3 suppresses growth of the murine melanoma B16 tumor in vivo. Cancer Res. 1999;59(20):5059-5063.

23. Ivanov VN, Bhoumik A, Krasilnikov M, et al. Cooperation between STAT3 and c-jun suppresses Fas transcription. Mo/ Cell. 2001;7(3):517-528.

24. Dang W, Tang $\mathrm{H}, \mathrm{Cao} \mathrm{H}$, et al. Strategy of STAT3 $\beta$ cell-specific expression in macrophages exhibits antitumor effects on mouse breast cancer. Gene Ther. 2015;22(12):977-983.

25. Zamo A, Chiarle R, Piva R, et al. Anaplastic lymphoma kinase (ALK) activates Stat3 and protects hematopoietic cells from cell death. Oncogene. 2002; 21(7):1038-1047.

26. Steensma DP, McClure RF, Karp JE, et al. JAK2 V617F is a rare finding in de novo acute myeloid leukemia, but STAT3 activation is common and remains unexplained. Leukemia. 2006;20(6):971-978.

27. Zhao J, Xu Y, Zong Y, et al. Inhibition of Stat3 expression induces apoptosis and suppresses proliferation in human leukemia HL-60 cells. Hematology. 2011;16(4):232-235.

28. Redell MS, Ruiz MJ, Alonzo TA, Gerbing RB, Tweardy DJ. Stat3 signaling in acute myeloid leukemia: ligand-dependent and -independent activation and induction of apoptosis by a novel small-molecule Stat3 inhibitor. Blood. 2011;117(21):5701-5709.

29. Benekli M, Xia Z, Donohue KA, et al. Constitutive activity of signal transducer and activator of transcription 3 protein in acute myeloid leukemia blasts is associated with short disease-free survival. Blood. 2002;99(1):252-257.

30. Irish JM, Hovland R, Krutzik PO, et al. Single cell profiling of potentiated phospho-protein networks in cancer cells. Cell. 2004;118(2):217-228.

31. Kornblau SM, Minden MD, Rosen DB, et al. Dynamic single-cell network profiles in acute myelogenous leukemia are associated with patient response to standard induction therapy. Clin Cancer Res. 2010;16(14):3721-3733.

32. Xia Z, Sait SN, Baer MR, et al. Truncated STAT proteins are prevalent at relapse of acute myeloid leukemia. Leuk Res. 2001;25(6):473-482.

33. Al Zaid Siddiquee K, Turkson J. STAT3 as a target for inducing apoptosis in solid and hematological tumors. Cell Res. 2008;18(2):254-267.

34. Epling-Burnette PK, Liu JH, Catlett-Falcone R, et al. Inhibition of STAT3 signaling leads to apoptosis of leukemic large granular lymphocytes and decreased Mcl-1 expression. J Clin Invest. 2001;107(3):351-362.

35. Lee H-J, Zhuang G, Cao Y, Du P, Kim HJ, Settleman J. Drug resistance via feedback activation of Stat3 in oncogene-addicted cancer cells. Cancer Cell. 2014;26(2):207-221.

36. Redell MS, Ruiz MJ, Gerbing RB, et al; Children's Oncology Group. FACS analysis of Stat3/5 signaling reveals sensitivity to G-CSF and IL-6 as a significant prognostic factor in pediatric AML: a Children's Oncology Group report. Blood. 2013;121(7):1083-1093.

37. Bruserud $\varnothing$, Nepstad I, Hauge M, Hatfield KJ, Reikvam H. STAT3 as a possible therapeutic target in human malignancies: lessons from acute myeloid leukemia. Expert Rev Hematol. 2015;8(1):29-41.

38. Lal R, Lind K, Heitzer E, et al. Somatic TP53 mutations characterize preleukemic stem cells in acute myeloid leukemia. Blood. 2017;129(18):2587-2591.

39. Grimwade D, Walker H, Oliver F, et al; The Medical Research Council Adult and Children's Leukaemia Working Parties. The importance of diagnostic cytogenetics on outcome in AML: analysis of 1,612 patients entered into the MRC AML 10 trial. Blood. 1998;92(7):2322-2333.

40. Döhner H, Estey E, Grimwade D, et al. Diagnosis and management of AML in adults: 2017 ELN recommendations from an international expert panel. Blood. 2017;129(4):424-447.

41. Spiekermann K, Bagrintseva K, Schwab R, Schmieja K, Hiddemann W. Overexpression and constitutive activation of FLT3 induces STAT5 activation in primary acute myeloid leukemia blast cells. Clin Cancer Res. 2003;9(6):2140-2150.

42. Yoshimoto G, Miyamoto T, Jabbarzadeh-Tabrizi S, et al. FLT3-ITD up-regulates MCL-1 to promote survival of stem cells in acute myeloid leukemia via FLT3-ITD-specific STAT5 activation. Blood. 2009;114(24):5034-5043.

43. Kotecha N, Flores NJ, Irish JM, et al. Single-cell profiling identifies aberrant STAT5 activation in myeloid malignancies with specific clinical and biologic correlates. Cancer Cell. 2008;14(4):335-343.

44. Choudhary C, Müller-Tidow C, Berdel WE, Serve H. Signal transduction of oncogenic Flt3. Int J Hematol. 2005;82(2):93-99.

45. Weisberg E, Barrett R, Liu Q, Stone R, Gray N, Griffin JD. FLT3 inhibition and mechanisms of drug resistance in mutant FLT3-positive AML. Drug Resist Updat. 2009;12(3):81-89.

46. Mizuki M, Schwable J, Steur C, et al. Suppression of myeloid transcription factors and induction of STAT response genes by AML-specific Flt3 mutations. Blood. 2003;101(8):3164-3173.

47. Blaas L, Musteanu M, Zenz R, Eferl R, Casanova E. PhiC31-mediated cassette exchange into a bacterial artificial chromosome. Biotechniques. 2007; $43(5): 659-660,662,664$

48. Yang XW, Model P, Heintz N. Homologous recombination based modification in Escherichia coli and germline transmission in transgenic mice of a bacterial artificial chromosome. Nat Biotechnol. 1997;15(9):859-865.

49. Yilmaz Ö, Valdez R, Theisen BK, et al. Pten dependence distinguishes haematopoietic stem cells from leukaemia-initiating cells. Nature. 2006; 441 (7092):475-482. 
50. Zhang J, Grindley JC, Yin T, et al. PTEN maintains haematopoietic stem cells and acts in lineage choice and leukaemia prevention. Nature. 2006; 441 (7092):518-522.

51. Poirel H, Rack K, Delabesse E, et al. Incidence and characterization of MLL gene (11q23) rearrangements in acute myeloid leukemia M1 and M5. Blood. 1996;87(6):2496-2505.

52. Matsuo Y, MacLeod RA, Uphoff CC, et al. Two acute monocytic leukemia (AML-M5a) cell lines (MOLM-13 and MOLM-14) with interclonal phenotypic heterogeneity showing MLL-AF9 fusion resulting from an occult chromosome insertion, ins(11;9)(q23;p22p23). Leukemia. 1997;11(9):1469-1477.

53. Kortlepel K, Bendall LJ, Gottlieb DJ. Human acute myeloid leukaemia cells express adhesion proteins and bind to bone marrow fibroblast monolayers and extracellular matrix proteins. Leukemia. 1993;7(8):1174-1179.

54. Reuss-Borst MA, Klein G, Waller HD, Müller CA. Differential expression of adhesion molecules in acute leukemia. Leukemia. 1995;9(5):869-874.

55. Liesveld JL. Expression and function of adhesion receptors in acute myelogenous leukemia: parallels with normal erythroid and myeloid progenitors. Acta Haematol. 1997;97(1-2):53-62.

56. De Waele M, Renmans W, Jochmans K, et al. Different expression of adhesion molecules on CD34+ cells in AML and B-lineage ALL and their normal bone marrow counterparts. Eur J Haematol. 1999;63(3):192-201.

57. Kupsa T, Vasatova M, Karesova I, Zak P, Horacek JM. Baseline serum levels of multiple cytokines and adhesion molecules in patients with acute myeloid leukemia: results of a pivotal trial. Exp Oncol. 2014;36(4):252-257.

58. Horacek JM, Kupsa T, Vasatova M, Jebavy L, Zak P. Biochip array technology and evaluation of serum levels of multiple cytokines and adhesion molecules in patients with newly diagnosed acute myeloid leukemia. Exp Oncol. 2014;36(1):50-51.

59. Extermann M, Bacchi M, Monai N, et al. Relationship between cleaved L-selectin levels and the outcome of acute myeloid leukemia. Blood. 1998;92(9): 3115-3122.

60. Stucki A, Rivier AS, Gikic M, Monai N, Schapira M, Spertini O. Endothelial cell activation by myeloblasts: molecular mechanisms of leukostasis and leukemic cell dissemination. Blood. 2001;97(7):2121-2129.

61. Spertini O, Callegari $\mathrm{P}$, Cordey AS, et al. High levels of the shed form of L-selectin are present in patients with acute leukemia and inhibit blast cell adhesion to activated endothelium. Blood. 1994;84(4):1249-1256.

62. Sackstein R. Expression of an L-selectin ligand on hematopoietic progenitor cells. Acta Haematol. 1997;97(1-2):22-28.

63. Hong S-H, Yang S-J, Kim T-M, et al. Molecular integration of HoxB4 and STAT3 for self-renewal of hematopoietic stem cells: a model of molecular convergence for stemness. Stem Cells. 2014;32(5):1313-1322.

64. Huang Y, Qiu J, Dong S, et al. Stat3 isoforms, $\alpha$ and $\beta$, demonstrate distinct intracellular dynamics with prolonged nuclear retention of Stat3 $\beta$ mapping to its unique C-terminal end. J Biol Chem. 2007;282(48):34958-34967.

65. Park OK, Schaefer LK, Wang W, Schaefer TS. Dimer stability as a determinant of differential DNA binding activity of Stat3 isoforms. J Bio/ Chem. 2000; 275(41):32244-32249.

66. Graf M, Reif S, Hecht K, et al. Low L-selectin (CD62L) expression in acute myeloid leukemia correlates with a bad cytogenetic risk. Eur J Haematol. 2003; 71(5):366-376. 